\title{
A mixed population of Helicobacter pylori, Helicobacter bizzozeronii and "Helicobacter heilmannii" in the gastric mucosa of a domestic cat
}

Rute Canejo-Teixeira*, Manuela Oliveira, Hugo Pissarra, Maria Manuela R E Niza and Christina L Vilela

\begin{abstract}
Background: The presence of Helicobacter within the gastric mucosa is responsible for producing pathology in many animal species, including man. Since humans have been shown to harbour many of the same bacterial species as domestic carnivores, concern over their zoonotic potential has been growing. Helicobacter pylori, a class 1 carcinogen responsible for cases of gastritis and gastric cancer in humans, produces similar pathology in pet carnivores and is considered an example of anthroponosis. The case here presented refers to a 13 year-old mixed breed spayed female cat seen at necropsy.

Findings: Stomach samples were analysed for the presence of Helicobacter spp. by cytology, histopathology and PCR. Mild mucosal atrophy was observed in the fundus and antrum, while lymphoplasmocytic infiltrates where noted in the lamina propria of the antrum. Helicobacter-like organisms were observed in the corpus and antrum, occupying gastric glands and surface mucosa. It was possible to detect Helicobacter spp., H. pylori, H. heilmannii and H. bizzozeronii in the fundus, corpus and antrum by PCR, while in the antrum PCR samples were positive for H. pylori.
\end{abstract}

Conclusions: The spayed female under study could represent either a yet un-described population of domestic cats infected with H. pylori or a case of anthroponosis.

Keywords: Feline, Helicobacter, Zoonosis, Gastritis, PCR, Histopathology

\section{Findings}

\section{Background}

Helicobacter pylori is a gram negative, urease positive, spiral bacteria classified by the World Health Organization as a class 1 carcinogen as its relationship to human gastritis and gastric cancer has been firmly established [1]. The majority of the 32 species described to date are enteric microorganisms of mammals, while 12 species are gastric inhabitants. Four species are now considered to be common in the gastric mucosa of domestic carnivores, Helicobacter felis, Helicobacter bizzozeronii, Helicobacter salomonis, "Helicobacter heilmannii" types 1, 2 and 4 [2,3], while the role of $H$. bilis' as a primary gastric organism remains questionable. Although the pathogenic role of these

\footnotetext{
* Correspondence: adrutecanejo@fmv.ulisboa.pt

Faculdade de Medicina Veterinária, Universidade de Lisboa, CIISA, Avenida da Universidade Técnica, Lisboa 1300-477, Portugal
}

species in gastritis and/or gastric cancer has yet to be firmly established in pets $[4,5]$, felines seem to be much more susceptible then canines [6]. Gastric fibroses and atrophy have been linked to $H$. felis infection in cats [7] while the presence of lymphoid follicles and inflammation have been related to Helicobacter spp. and "H. heilmannii" senso lato colonization $[8,9]$.

It has been suggested that, similarly to $H$. pylori infected humans, the presence of $H$. heilmannii could play a role in feline alimentary lymphoma [10]. There are several reasons for the growing concern regarding the zoonotic potential of these bacteria [11]. Firstly, humans have been shown to harbour species other than H. pylori with pathological consequences; secondly, no environmental source for these bacteria has been found; and lastly, epidemiological studies have shown a link between animal contact and infection [12]. Although $H$. pylori 
produces similar pathology in pet carnivores and in humans, this species has yet to be found in normal domestic carnivore populations [13,14], making these cases good examples of anthroponosis [4,6,13]. However, Buczolits et al. [15] have identified two sequences from Helicobacter-like organisms $100 \%$ identical to $H$. pylori in the gastric mucosa of canines, re-kindling the debate on the role of pet carnivores in the transmission of this bacterium to humans. The present work describes the presence of $H$. pylori in a mixed population of Helicobacter species in the gastric mucosa of a domestic short-hair cat.

\section{Case presentation}

A 13 year-old mixed breed spayed female cat with a history of mammary tumors and pleural effusion, euthanized at the owners' request, was presented for necropsy to the Pathology Department of the Faculty of Veterinary Medicine, University of Lisbon. The stomach was opened along the greater curvature, brush cytology was performed and four full thickness biopsies where obtained from the fundus, corpus and antrum for histopathology and PCR analyses. Brush cytologies where obtained using sterile, single use inoculation loops and stained with May-Grünwald-Giemsa. One biopsy from each gastric region was stored in $10 \%$ formalin for histology processing. A combined sample, comprising one sample from each region, and the remaining biopsies from the three regions were kept frozen at $-80^{\circ} \mathrm{C}$, until DNA extraction with Qiagen DNeasy ${ }^{\circledR}$ Blood \& Tissue Kit, according to the manufacturer's instructions. PCR reactions for Helicobacter spp., $H$. pylori, H. felis, $H$. heilmannii, $H$. bizzozeronii, $H$. salomonis and $H$. bilis were performed as previously described [3,7,16-19], using Fidel$\mathrm{Taq}^{\mathrm{TM}}$ MasterMix (USB ${ }^{\circ}$ Products - Affymetrix, Inc.). Reference strains $H$. pylori CCUG 17874 T, $H$. felis ATCC 49179, H. bizzozeronii CCUG 35045, H. salomonis CCUG 37845, H. bilis ATCC 51630 and H. heilmannii DNA (kindly provided by Professor K.W. Simpson) were used as positive controls. Biopsies for histopathology were imbedded in paraffin blocks, processed and stained with Hematoxylin and Eosin and with Giemsa.

Based on the World Small Animal Veterinary Association histopathological standards [20], mild mucosal atrophy was observed in the fundus and antrum, while moderate lymphoplasmocytic infiltrates were noted in the lamina propria of the antrum. Helicobacter-like organisms were observed in the corpus and antrum, occupying gastric glands and surface mucosa (Figure 1A), where colonization was classified as mild. Brush cytology was positive in the fundus and corpus (Figure 1B), but negative in the antrum. PCR performed using DNA extracted from the combined sample was positive for Helicobacter spp., $H$. pylori, $H$. heilmannii and $H$. bizzozeronii, originating 1200-bp, 298-bp, 580-bp and 420-bp amplicons, respectively (Figure 2). When tested individually, the three regions were positive for Helicobacter spp., $H$. heilmannii and $H$. bizzozeronii, while only the antrum was positive for H. pylori.

\section{Conclusions}

The presence of a Helicobacter mixed population has been previously described in feline gastric biopsies [21].

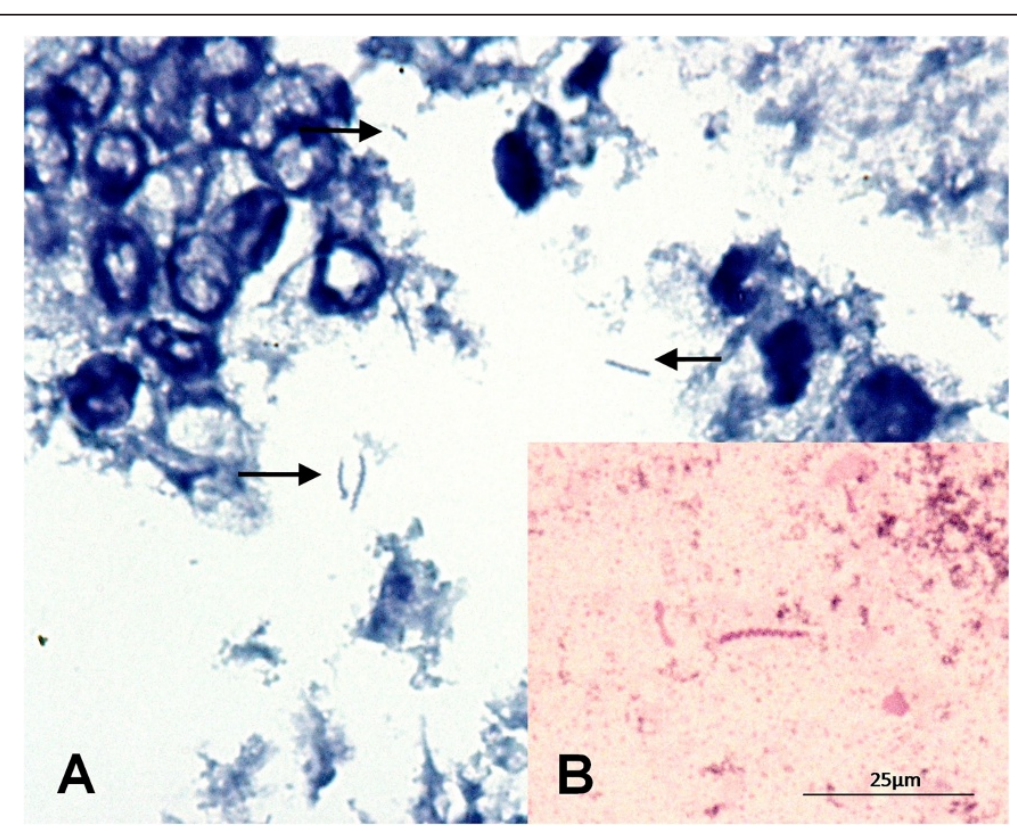

Figure 1 Spiral bacteria, consistent with Helicobacter spp. found in the stomach (A) in the surface mucosa. 1000x. Giemsa. (B) and brush cytology of the fundus region. 1000x. May-Grünwald-Giemsa. (Original photographs). 


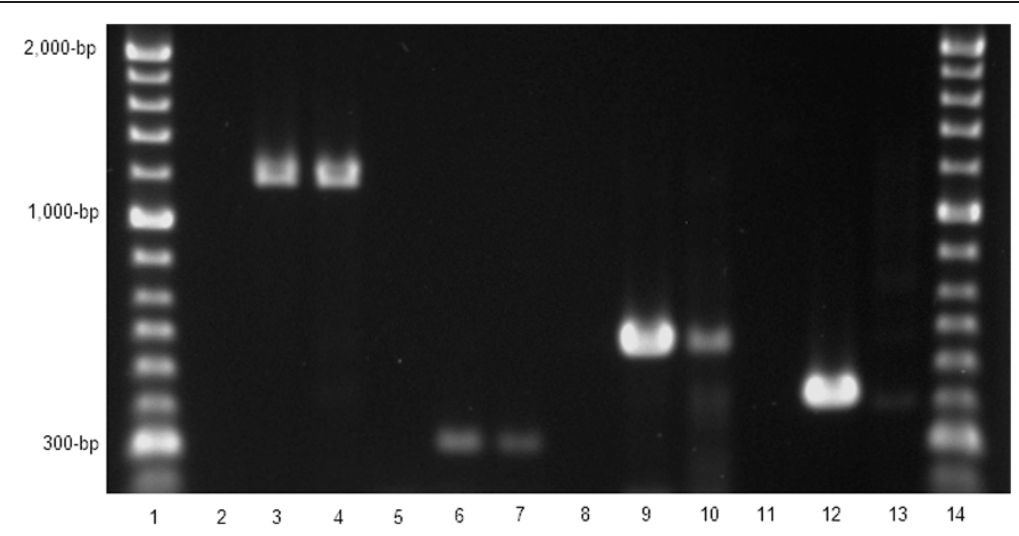

Figure 2 PCR reactions. Molecular ladder in lane 1 and 14 (Hyperladder II ${ }^{\mathrm{TM}}$ Bioline); negative controls in lane 2, 5, 8 and 11; positive controls Helicobacter spp. (lane 3 using H. felis ATCC 49179), H. pylori (lane 6), H. heilmannii type 2 (lane 9), H. bizzozeronii (420-bp, lane 12); sample results H. spp (1,200-bp, lane 4), H. pylori (298-bp, lane 7), H. heilmannii (580-bp, lane 10) and H. bizzozeronii (420-bp, lane 13).

Our finding of mild mucosal atrophy is consistent with other studies [6,22]; however Simpson et al. [7] linked changes in the architecture of the gastric mucosa with the presence of $\mathrm{H}$. felis, a species not found in this cat. $H$. heilmannii has been shown to alter gastric architecture but through epithelial proliferation and lymphoid follicular hyperplasia [9], not atrophy. It is possible however that the presence of $H$. pylori and H. bizzozeronii altered the pathogenic capacity of $H$. heilmannii as described for mixed infections of $\mathrm{H}$. bizzozeroniiI/H. felis [11]. The fact that the fundus and antrum were the most affected regions is consistent with others findings [8] and, although not characteristic, the presence of inflammation in the antrum is similar to that found in felines experimentally infected with $H$. pylori [21].

The occurrence of $H$. pylori in the gastric mucosa of felines has been only reported in a particular commercial breeder [23] but not in stray and domestic populations $[13,14,24]$. The spayed female under study could represent either a yet un-described population of domestic cats infected with $H$. pylori or a case of anthroponosis, as hypothesized by some authors [4,5,13]. Considering $H$. pylori's ability to survive in water [25] and the tendency for keeping indoor/outdoor cats in Portugal, colonization of this animal through a contaminated water source must also be considered. It was not possible to determine whether human co-inhabitants were H. pylori positive or if the animal had outdoor access.

The presence of $H$. heilmannii in cats has been linked to various alterations in gastric mucosa [9] and alimentary lymphoma [10]. Jergens et al. [22] have shown that treatment leads to the improvement of gastritis clinical signs and bacterial clearance, although histological signs of gastritis remain, suggesting a causal relationship similar to that seen in H. pylori infected humans [16]. However, as other studies could not evidence such relationship, other factors such as the effect of mixed infections and the possibility of strain dependent virulence, should be considered. The presence of a mixed infection of $H$. heilmannii and H. pylori, as found in this cat, could explain the development of pathology in some animals and not in others infected only with $H$. heilmannii. Given $H$. pylori's focal distribution pattern [6], the small sample size normally obtained through endoscopy and even biopsy [21] may explain the high rate of negative results for $H$. pylori.

The role played by Helicobacter in feline gastritis, associated or not with lymphoma, remains controversial. Several factors, such as the species of Helicobacter present, the virulence of the strain, and the genetic predisposition of the animal, should be further investigated in order to better understand their relation to clinical disease.

\section{Abbreviations}

PCR: Polymerase chain reaction; DNA: Deoxyribonucleic acid; Bp: Base-pairs.

Competing interests

The authors declare that they have no competing interests.

\section{Authors' contributions}

$\mathrm{RCT}$ identified the patient, collected the gastric samples and performed brush cytology. RCT and MO carried out the laboratory processes that permitted the processing of samples for PCR analyses. HP performed the histopathology. RCT and CLV were involved in data acquisition, analysis and interpretation and the drafting of the manuscript. MMREN was involved in revising the manuscript, contributing to its intellectual content. All authors read and approved the final manuscript.

\section{Acknowledgements}

The authors would like to thank CIISA/FMV for their financial support (Project PEst-OE/AGR/U10276/2014, funded by FCT), Professor Kenneth W. Simpson for the kind donation of $\mathrm{H}$. heilmannii DNA used as a positive control for PCR, Professor Maria Conceição Peleteiro for her expert advice, as well as and Tec. Sandra Carvalho for her assistance with histopathology and Tec. Carla Carneiro for her assistance in the bacteriology laboratory.

Received: 14 April 2014 Accepted: 1 October 2014

Published: 19 November 2014 


\section{References}

1. Cover TL, Blaser MJ: Helicobacter pylori in Health and Disease. Gastroenterology 2009, 136:1863-1873.

2. O'Rourke JL, Solnick JV, Neilan BA, Seidel K, Hayter R, Hansen LM, Lee A: Description of 'Candidatus Helicobacter heilmannii' based on DNA sequence analysis of $16 \mathrm{~S}$ rRNA and urease genes. Int I Syst Evol Microbiol 2004, 54:2203-2211.

3. Priestnall SL, Wiinberg B, Spohr A, Neuhaus B, Kuffer M, Wiedmann M, Simpson KW: Evaluation of "Helicobacter heilmannii" subtypes in the gastric mucosas of cats and dogs. J Clin Microbiol 2004, 42:2144-2151.

4. Solnick JV, Schauer DB: Emergence of diverse Helicobacter species in the pathogenesis of gastric and enterohepatic diseases. Clin Microbiol Rev 2001, 14:59-97.

5. Harbour S, Sutton P: Immunogenicity and pathogenicity of Helicobacter infections of veterinary animals. Vet Immunol Immunopathol 2008, 122:191-203.

6. Neiger R, Simpson KW: Helicobacter infection in dogs and cats: facts and fiction. J Vet Intern Med 2000, 14:125-133.

7. Simpson KW, Strauss-Ayali D, Scanziani E, Straubinger RK, McDonough PL, Straubinger AF, Chang YF, Domeneghini C, Arebi N, Calam J: Helicobacter felis infection is associated with lymphoid follicular hyperplasia and mild gastritis but normal gastric secretory function in cats. Infect Immun 2000, 68:779-790.

8. Strauss-Ayali D, Scanziani E, Deng D, Simpson KW: Helicobacter spp. infection in cats: evaluation of the humoral immune response and prevalence of gastric Helicobacter spp. Vet Microbiol 2001, 79:253-265.

9. Takemura LS, Camargo PL, Alfieri AA, Bracarense AP: Helicobacter spp. in cats: association between infecting species and epithelial proliferation within the gastric lamina propria. J Comp Pathol 2009, 141:127-134.

10. Bridgeford EC, Marini RP, Feng Y, Parry NM, Rickman B, Fox JG: Gastric Helicobacter species as a cause of feline gastric lymphoma: a viable hypothesis. Vet Immunol Immunopathol 2008, 123:106-113.

11. Haesebrouck F, Pasmans F, Flahou B, Chiers K, Baele M, Meyns T, Decostere A, Ducatelle R: Gastric helicobacters in domestic animals and nonhuman primates and their significance for human health. Clin Microbiol Rev 2009, 22:202-223. Table of Contents.

12. Meining A, Kroher $G$, Stolte $M$ : Animal reservoirs in the transmission of Helicobacter heilmannii. Results of a questionnaire-based study. Scand J Gastroenterol 1998, 33:795-798.

13. El-Zaatari FA, Woo JS, Badr A, Osato MS, Serna H, Lichtenberger LM, Genta RM, Graham DY: Failure to isolate Helicobacter pylori from stray cats indicates that $\mathrm{H}$. pylori in cats may be an anthroponosis-an animal infection with a human pathogen. J Med Microbiol 1997, 46:372-376.

14. Ghil HM, Yoo JH, Jung WS, Chung TH, Youn HY, Hwang CY: Survey of Helicobacter infection in domestic and feral cats in Korea. J Vet Sci 2009, 10:67-72.

15. Buczolits S, Hirt R, Rosengarten R, Busse HJ: PCR-based genetic evidence for occurrence of Helicobacter pylori and novel Helicobacter species in the canine gastric mucosa. Vet Microbiol 2003, 95:259-270.

16. Perkins SE, Yan LL, Shen Z, Hayward A, Murphy JC, Fox JG: Use of PCR and culture to detect Helicobacter pylori in naturally infected cats following triple antimicrobial therapy. Antimicrob Agents Chemother 1996, 40:1486-1490.

17. Simpson KW, McDonough PL, Strauss-Ayali D, Chang YF, Harpending P, Valentine BA: Helicobacter felis infection in dogs: effect on gastric structure and function. Vet Pathol 1999, 36:237-248.

18. Mikkonen TP, Karenlampi RI, Hanninen ML: Phylogenetic analysis of gastric and enterohepatic Helicobacter species based on partial HSP60 gene sequences. Int I Syst Evol Microbiol 2004, 54:753-758.

19. Feng S, Ku K, Hodzic E, Lorenzana E, Freet K, Barthold SW: Differential detection of five mouse-infecting helicobacter species by multiplex PCR. Clin Diagn Lab Immunol 2005, 12:531-536.

20. Day MJ, Bilzer T, Mansell J, Wilcock B, Hall EJ, Jergens A, Minami T, Willard M, Washabau R: Histopathological standards for the diagnosis of gastrointestinal inflammation in endoscopic biopsy samples from the dog and cat: a report from the World Small Animal Veterinary Association Gastrointestinal Standardization Group. J Comp Pathol 2008, 138(Suppl 1):S1-S43.

21. Scanziani E, Simpson KW, Monestiroli S, Soldati S, Strauss-Ayali D, Del Piero F: Histological and immunohistochemical detection of different Helicobacter species in the gastric mucosa of cats. J Vet Diagn Invest 2001, 13:3-12.
22. Jergens AE, Pressel M, Crandell J, Morrison JA, Sorden SD, Haynes J, Craven $M$, Baumgart M, Simpson KW: Fluorescence in situ hybridization confirms clearance of visible Helicobacter spp. associated with gastritis in dogs and cats. J Vet Intern Med 2009, 23:16-23.

23. Handt LK, Fox JG, Dewhirst FE, Fraser GJ, Paster BJ, Yan LL, Rozmiarek $H$, Rufo $\mathrm{R}$, Stalis IH: Helicobacter pylori isolated from the domestic cat: public health implications. Infect Immun 1994, 62:2367-2374

24. Shojaee Tabrizi A, Jamshidi S, Oghalaei A, Zahraei Salehi T, Bayati Eshkaftaki A, Mohammadi M: Identification of Helicobacter spp. in oral secretions vs. gastric mucosa of stray cats. Vet Microbiol 2010, 140:142-146.

25. Azevedo NF, Almeida C, Fernandes I, Cerqueira L, Dias S, Keevil CW, Vieira MJ: Survival of gastric and enterohepatic Helicobacter spp. in water: implications for transmission. Appl Environ Microbiol 2008, 74:1805-1811.

doi:10.1186/2046-0481-67-25

Cite this article as: Canejo-Teixeira et al:: A mixed population of Helicobacter pylori, Helicobacter bizzozeronii and "Helicobacter heilmannii" in the gastric mucosa of a domestic cat. Irish Veterinary Journal 2014 67:25.

\section{Submit your next manuscript to BioMed Central and take full advantage of:}

- Convenient online submission

- Thorough peer review

- No space constraints or color figure charges

- Immediate publication on acceptance

- Inclusion in PubMed, CAS, Scopus and Google Scholar

- Research which is freely available for redistribution

Submit your manuscript at www.biomedcentral.com/submit
Ciomed Central 